\title{
Value on Surface Electrocardiogram for the Right Free Wall in Localizing Accessory Pathway by Simple Parameters in Typical Wolff- Parkinson-White Syndrome
}

\author{
Si Dung Chu' ${ }^{1,2 *}$, Khanh Quoc Pham ${ }^{1,2}$ and Dong Van Tran ${ }^{2}$ \\ ${ }^{1}$ School of Medicine and Pharmacy, Vietnam National University, Vietnam \\ ${ }^{2}$ Vietnam Heart Institute, Bachmai Hospital, Vietnam
}

Submission: September 05, 2018; Published: September 27, 2018

*Corresponding author: Si Dung Chu, School of Medicine and Pharmacy, Vietnam National University, Hanoi \& Vietnam National Heart Institute, Bachmai Hospital, Y1 Buidling, 144 XuanThuy Str., CauGiay Dist., Hanoi, Vietnam, Tel: +84 906086168, Email: Dr.Swiss.zhu@gmail.com/ chudungsi@gmail.com

\begin{abstract}
Objectives: This study was designed to characteristics of surface 12-lead Electrocardiogram (ECG) for the right free wall lateral of accessory pathway (AP) localization in the typical WPW syndrome to develop a new algorithm ECG for the right free wall in localizing APs, and to test the accuracy of the algorithm prospectively. Methods: We studied 90 patients, in 40 patients with typical WPW syndrome have a single anterogradely with the localization of right free wall APs identified by successful radiofrequency catheter ablation (RCFA) to develop a new ECG algorithm for the right free wall in localizing APs. Then this algorithm was tested prospectively in 50 patients were compared with the location of AP's successful ablation by RCFA. Results: We found that the 12 lead ECG parameters in typical WPW syndrome such as delta wave polarity in V1, the transition of the QRS complex, delta wave polarity and QRS complex polarity in inferior leads in diagnosis for the localization of APs by with high accuracy predicted from $80 \%$ to $100 \%$, and for development of a new ECG algorithm. The following 50 patients were then prospectively evaluated by the new derived algorithm with high sensitivity and specificity from $91.3 \%$ to $100 \%$, with strongly relationship between ECG and AP localization ( $p<0.0001)$. Conclusion: 12-lead ECG parameters in typical WPW syndrome closely related to right free wall of APs localization, in order to develop the new ECG algorithm by simple parameters as above; and can be used to a new ECG parameter in predicted the location APs with high accuracy predicted.
\end{abstract}

Keywords: Surface ECG; Right free wall; Accessory pathway Localization; WPW syndrome

Abbreviations: ECG: Electrocardiogram; AP: Accessory Pathway; RCFA: Radiofrequency Catheter Ablation; RA: Right Anterolateral; TA: Tricuspid Annulus; MA: Mitral Annulus; HIS: His Bundle; CS: Coronary Sinus; RIP: Right Inferior Paraseptal

\section{Introduction}

Wolff-Parkinson-White syndrome (WPW) caused by ventricular pre-excitation via an accessory pathways (APs) that bypass the atrioventricular $(\mathrm{AV})$ node, establishing a direct link between the atrium and the ventricle (called Kent Bundle); Conduction may be anterograde, retrograde, or both. The 12-lead ECG is characterized by a shortened PR, prolonged QRS, with Delta wave [1,2].

Arrhythmias are most common in WPW syndrome patients. Nowadays, Radio Frequency Catheter Ablation (RCFA) of Accessory Pathway (AP) requires precise localization of the AP along the mitral and tricuspid annulus (gold standard) [2]. 12lead ECG is the first step for localization of AP in patients with WPW syndrome, still now. While incremental improvements in skills of doctors as well as catheter design or mapping systems will undoubtedly facilitate ablative procedures, the data Obtained from the ECG parameters can be helpful in planning and shortening the RCFA procedure and fluoroscopy time [2].

Furthermore, according to many studies, the right free wall (the side of the tricuspid vale circle, except the septal location) is rather difficult in catheter ablation procedures by RF. Localizing accessory pathways for the right free wall as includes right anterolateral, right lateral, right posterolateral pathways can help the quickly of approach to a accessory pathway location to facilitate mapping and shorten time radiofrequency ablation [15]. 


\section{Journal of Cardiology \& Cardiovascular Therapy}

Some ECG algorithms based have been published predicting locations of right free wall accessory pathways [6-9]. However, many studies showed that difficult to compared in different between other locations in the side of tricuspid valve circle [1013]. Therefore, the purpose of this study was to analyse the 12lead ECG of right lateral free wall accessory pathway localization's successful RCFA to develop new ECG algorithm using simple parameters and test this algorithm to predict accessory pathway location.

\section{Subject and Methods}

\section{Study design}

Observational, cross-sectional, retrospective and prospective study.

\section{Study contents}

We studied 90 patients with typical WPW syndrome have a single right free wall of accessory pathway from January 2001 to November 2017 at Vietnam Heart Institute, Bachmai Hospital. 40 patients with typical WPW syndrome who had a single anterograde right free wall of AP identified by successful radio frequency catheter ablation were enrolled to build a new ECG algorithm for localizing right free wall APs using simple parameters from January 2001 to June 2016. Then this algorithm was tested prospectively in 50 patients were comparing with the location of right free wall of accessory pathway's successful ablation by RF from June 2016 to November 2017.

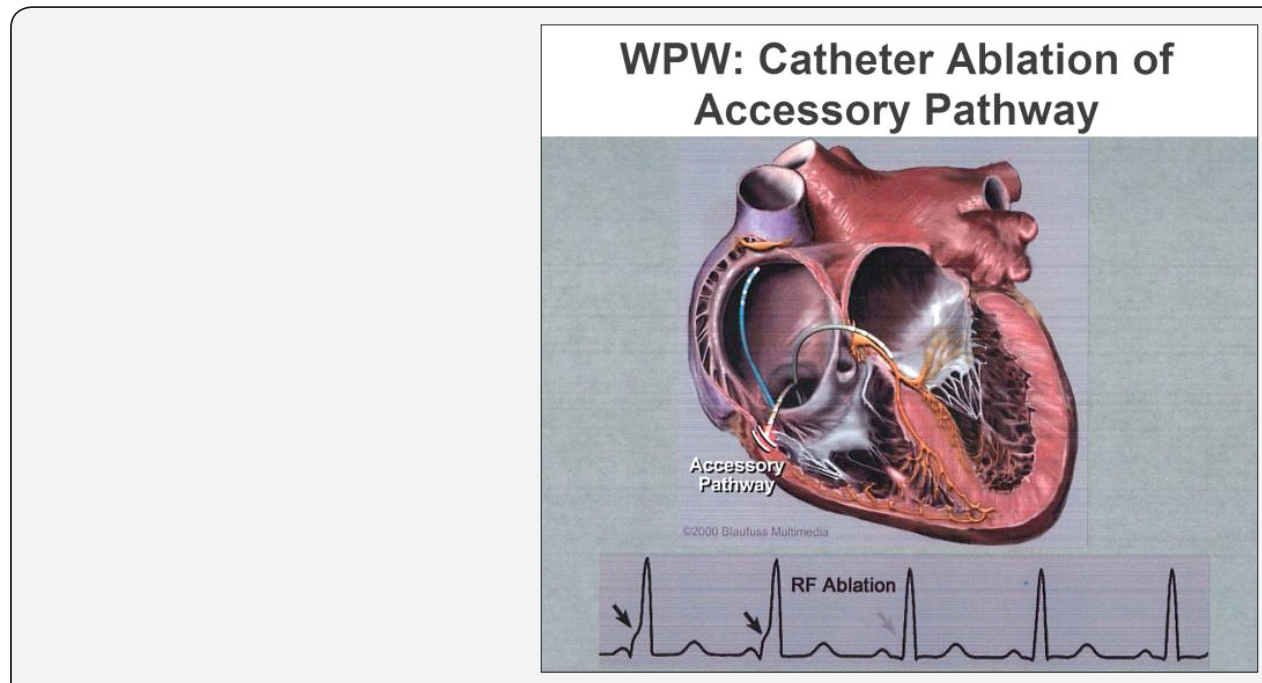

Figure 1: Schema showing use of catheter technique for ablation of a right free wall accessory pathway: The rhythm strip shows disappearance of the delta wave with application of radiofrequency energy [1].

WPW syndrome was defined as the 12-lead ECG is characterized by a shortened PR interval $<120$ milliseconds, prolonged QRS duration $\geq 110$ milliseconds, with a delta wave (small slurred upstroke at the beginning of the QRS). Secondary ST and T wave changes which are directed opposite to the major Delta wave and QRS vector [1]. Localization of accessory pathways was identified by successfully ablated by RCFA (gold standard) [2] (Figure 1).

\section{Statistical Analysis}

Using IBM SPSS 21.0 software for analyzing data [14,15].

\section{Results}

The study population consists of 90 patients, 42 men (46.7\%) and 48 female (53.3\%), mean age $37.7 \pm 13.5$ years (from 18 to 75 years of age) (Figure 2).

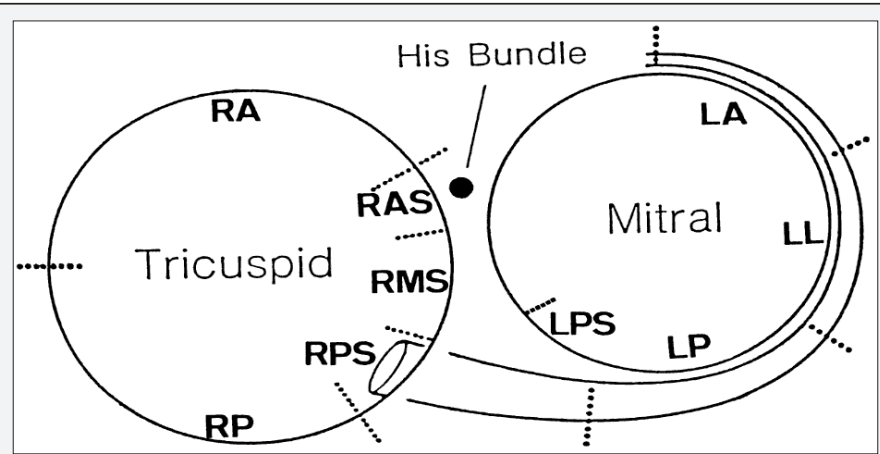

Figure 2: Anatomic definition of accessory pathway location. A schematic diagram of the heart from the left anterior oblique projection shows the relation among the tricuspid annulus (TA), mitral annulus (MA), His bundle (HIS), coronary sinus (CS), and the anatomic locations of the accessory pathways. Accessory pathway locations are divided into 10 main regions, LA: left anterior lateral; LL: left lateral; LP: left posteriorlateral; LPS: left posteroseptal; MS: midseptal; RPS: right posteroseptal; RA: right anteriorlateral; RAS: right anteroseptal; RL: right lateral; RP: right posteriorlateral. 


\section{Characteristic of 12-lead ECG for localization of right free wall accessory pathways}

The study of "the Fist group" consists of 40 patients (Group I), 20 men (50\%) and 20 females (50\%), mean age $39.0 \pm 14.0$ years [18: 75 years]. The Right free wall of accessory pathways was found in 40 patients with $9 / 40$ patients had right anterolareal (22.5\%), 10/40 patient had right lateral (25\%), and 21/40 patients had right posterolateral (52.5\%).

\section{Characteristic of 12-lead ECG for localization of right free wall accessory pathways}

The study of "the Fist group" consists of 40 patients (Group I), 20 men (50\%) and 20 females (50\%), mean age $39.0 \pm 14.0$ years [18: 75 years]. The Right free wall of accessory pathways was found in 40 patients with 9/40 patients had RAL (22.5\%), 10/40 patient had RL (25\%), and 21/40 patients had RPL (52.5\%).

Characterization of the QRS complex transition on 12lead ECG with right free wall location: Classified transition of right free wall location was most common at after V1, V2 lead (V3-V6) found in 36 of 40 patients with right free wall pathways (90\%).

Characterization of delta wave polarity in V1 lead with right free wall location: Right free wall pathways had negative delta wave was most common at V1 lead found in 32 of 40 patients $(80 \%)$.

Beside, Right free wall pathways had negative delta wave was most common at $\mathrm{V} 1$ lead found in 40 of 40 patients (100\%).

Characterization of delta wave polarity and QRS complex polarity in at least $2 / 3$ inferior lead with other positions of right free wall location: RAL pathways had positive delta wave was most common in at least $2 / 3$ inferior lead (DII, DIII, AVF) found in 9 of 9 patients (100\%); while RPL pathways had negative delta wave was most common in at least $2 / 3$ inferior lead found in 20 of 21 patients (95.2\%). Beside, RL pathways had negative delta wave was most common in at least $2 / 3$ inferior lead found in 9 of 10 patients (90\%). Thus, both in includes RL/RPL pathways had negative delta wave was most common in at least $2 / 3$ inferior lead found in 29 of 31 patients (93.5\%), while only RAL pathways had positive delta wave was most common in at least $2 / 3$ inferior lead (100\%) as above.

Classified QRS complex polarity of inferior lead (DII, DIII, $\mathrm{aVF}$ ) for the RL pathways and RPL pathways: RL region was most common with positive QRS complex in at least 2/3 inferior lead was found in 9 of 10 patients (90\%). While, RPL region was most common with negative QRS complex in at least 2/3 inferior lead was found in 20 of 21 patients (95.2\%) (Table 1).

Table 1: Characterization of delta wave in V1 lead, QRS complex transition at after V1V2 (V3-V6), delta

\begin{tabular}{|c|c|c|c|c|}
\hline \multirow{2}{*}{$\begin{array}{c}\text { Characterization } \\
\text { Right free wall }\end{array}$} & \multirow{2}{*}{$\begin{array}{l}\text { (+/-) Delta wave } \\
\text { in V1 }\end{array}$} & \multirow{2}{*}{$\begin{array}{c}\text { QRS complex } \\
\text { transition at } \\
\text { V1V2/or after V2 }\end{array}$} & \multicolumn{2}{|c|}{$\begin{array}{l}(+/-) \text { Delta wave/QRS complex } \\
\text { in at least } 2 / 3 \text { inferior lead }\end{array}$} \\
\hline & & & $\begin{array}{c}\text { (+/-) Delta wave in at least 2/3 } \\
\text { inferior lead }\end{array}$ & $\begin{array}{c}(+/-) \text { QRS complex in at least 2/3 inferior } \\
\text { lead }\end{array}$ \\
\hline Right anterolateral & $(-)$ & After V1V2 & $(+)$ & $(+)$ \\
\hline Right lateral & $(-)$ & After V1V2 & $(-)$ & $(+)$ \\
\hline Right Posterolateral & $(-)$ & After V1V2 & $(-)$ & $(-)$ \\
\hline
\end{tabular}

wave/QRS complex polarity in at least 2/3 inferior lead.

Note: (+): positive delta wave/QRS complex polarity; (-): negative delta wave/QRS polarity.

\section{Accuracy of new ECG algorithm for the right free wall in localizing accessory pathway}

The study of the second group consists of 50 patients (Group II), 22 men (44.0\%) and 28 female (56.0\%), mean age $36.7 \pm 13.1$ years [19: 69]. Right free wall pathways was found in 50 patients with 14 of 50 patients had RAL region (28.0\%), 13 of 50 patients had RL region (26.0\%), 23 of 50 patients had RPL region (46.0\%).
Localization of free wall lateral locations accessory pathways group by transition characteristics of the QRS complex on 12-lead ECG: Accuracy of the algorithm for localizing APs in right free wall location by QRS complex transition was most common at after V1V2 lead (V3-V6) found in 47 of 50 patients (94.0\%), giving a sensitivity of $94.0 \%$ (Table 2 ).

Table 2: Characterization of QRS complex transition in at least 2/3 inferior lead (DII, DIII, aVF).

\begin{tabular}{|c|c|c|c|c|c|c|c|c|}
\hline \multirow{2}{*}{$\begin{array}{c}\text { Location } \\
\text { QRS transition position }\end{array}$} & \multicolumn{2}{|c|}{$\begin{array}{c}\text { Right antero } \\
\text { lateral (n) }\end{array}$} & \multicolumn{2}{|c|}{$\begin{array}{c}\text { Right lateral } \\
\text { (n) }\end{array}$} & \multicolumn{2}{c|}{$\begin{array}{c}\text { Right postero } \\
\text { lateral (n) }\end{array}$} & \multicolumn{2}{c|}{ Total } \\
\cline { 2 - 9 } & $\mathbf{n}$ & $\mathbf{\%}$ & $\mathbf{n}$ & $\mathbf{\%}$ & $\mathbf{n}$ & $\mathbf{\%}$ & $\mathbf{N}$ & $\mathbf{\%}$ \\
\hline QRS Transition in V1V2 (before V3) & 0 & 0 & 0 & 0.0 & 3 & 13.0 & 3 & $6.0 \%$ \\
\hline QRS Transition after V1V2 (V3-V6) & 14 & 100 & 13 & 100.0 & 20 & 87.0 & 47 & $94.0 \%$ \\
\hline Total (n) & $\mathbf{1 4}$ & & $\mathbf{1 3}$ & & $\mathbf{2 3}$ & & $\mathbf{5 0}$ & \\
\hline
\end{tabular}


Localization of right accessory pathway pathways by delta wave polarity in V1 lead: Accuracy of the algorithm for localizing APs in right free wall pathways belong to right side location by negative delta wave in V1 lead found in 49 of 50 patients (98.0\%), giving a sensitivity of $98.0 \%$. Accuracy of the algorithm for localizing APs in right free wall pathways belong to right side location by negative QRS complex in V1 lead found in 50 of 50 patients (98.0\%), giving a sensitivity of $100.0 \%$.

Localization of other position of right free wall pathways (RAL, RL, RPL): Accuracy of the algorithm for localizing APs in group of RAL pathways or RPL pathways by positive/negarive delta wave in at least 2/3 inferior lead were 14 of $14(100 \%)$ and 23 of $23(100 \%)$, giving a sensitivity of $100 \%$, specificity of $100 \%$, PPV of $100 \%$ and NPV of $100 \%(R=1.0, P<0.0001)$. Muhammad showed that the Antero or postero accessory pathways by positive/negative delta waves in common at inferior lead had Se and Sp from 85-100\% [9].

Accuracy of the algorithm for localizing APs in RAL region or includes RL/RPL region by positive or negative delta wave in at least 2/3 inferior lead were 14 of 14 (100\%) and 35 of 36 (97.2\%), giving a sensitivity of $100 \%$, specificity of $97.2 \%$, PPV of 93.3\% and NPV of $100 \%$ with $R=0.953$ ( $p=0.0001)$.

Accuracy of the algorithm for localizing APs in group of RAL pathways or RPL pathways by positive/negative QRS complex in at least $2 / 3$ inferior lead were 14 of $14(100 \%)$ and 21 of 23 (91.3\%), giving a sensitivity of $100 \%$, specificity of $91.3 \%$, PPV of $87.5 \%$ and NPV of $100 \%(\mathrm{R}=0.894, \mathrm{P}<0.0001)$.

Different between the includes RAL/RL region with RPL region by positive or negative QRS complex in at leat 2/3 inferior lead with high accuracy, giving a sensitivity of $96.3 \%$, specificity of $91.3 \%$, PPV of $92.9 \%$ and NPV of $95.5 \%$, with R $=0.824$ ( $p=$ 0.0001). Furthermore, different between the RL region and RPL region by positive or negative QRS complex in at least 2/3 inferior lead with high accuracy, giving a sensitivity of $92.3 \%$, specificity of $91.3 \%$, PPV of $85.7 \%$ and NPV of $95.5 \%$, with $\mathrm{R}=0.824$ ( $\mathrm{p}=$ $0.0001)$.

Patients $(n=50)$ with right free wall accessory pathways required less procedure time for ablation was $50.2 \pm 11.5$ minutes [30:70], ablation time was $426.9 \pm 225.1 \mathrm{~ms}$ [231:1088] and less fluoroscopy time was $6.9 \pm 3.0$ minutes [3:15].

\section{Discussion}

\section{Characterization}

Transition characteristics of the QRS complex on 12lead ECG with right free wall location: Classified transition of right free wall location was most common at after V1V2 (V3V6) lead are noted (90\%); while only $10 \%$ patients had QRS complex transition at V1V2 lead. This is a characteristic can be different between the free wall lateral and septal location. Some studies were showed that QRS complex transition can be used to predicting locations of septal or free wall accessory pathway but almost these studies focus on some position of right free wall or right septal $[1,6,7]$. Muhammad [9] showed that right free wall location had transition was most common at after V3 lead. Thus, we can predict right free wall belong to free wall location by QRS transition in the after V1V2 lead [9].

Characterization of delta wave polarity in V1 lead with right free wall: Right free wall had negative delta wave was most common at V1 lead (80\%); This is very useful in selecting the approach of the catheter is the vein or artery. Right-side AP were ablated with retrograde vein approach (while left-sided AP were ablated with the use of transvenous atrial approach through the femoral artery) [2].

Although characterization of the negative QRS complex in the right free wall lateral pathways is very high, we think that it would be difficult to determine the right free wall lateral pathways by negative QRS complex, because infact in reality the following the left free wall lateral pathways as well as the left septal side are very common with the negative $\mathrm{QRS}$ complex $(\mathrm{R} / \mathrm{S}$ ratio $<1)$ which the negative QRS characterization; while the delta wave are more distinguishable between right or left side $[12,13]$. Thus, we used to the negative delta wave in lead V1 for the predicting to the right side.

Some ECG algorithms have been published predicting locations of left-sided or right-sided accessory pathway by positive of negative delta wave [1,2]. However, some other studies showed that diagnosis left or right-side accessory pathway by other ECG parameters such as D' Avila was used to positive or negative QRS complex in V1 can be diagnosis left or right-side APs [6]. Chern-En Chiang showed that $\mathrm{R} / \mathrm{S}$ ratio $<1$, suggested that was in the rightside APs [7]. Mauricio S. Arruda (1998) also found that R/S $>1$ in $\mathrm{V} 1$ lead was the left free location and $\mathrm{R} / \mathrm{S}<1$ in V1 lead was the right side [8]. Muhammad [9] also used a R/S ratio $<1$ in a VL lead to predict left side [9]. Noriko was used to $\mathrm{R} / \mathrm{S}$ ratio $<0.5$ or $\mathrm{R} / \mathrm{S}>$ 0.5 in V1 lead can be predicting right or left-side AP [13]. We were not used to the $\mathrm{R} / \mathrm{S}$ ratio at a VL lead as well as $\mathrm{R} / \mathrm{S}$ ratio (or QRS) in $\mathrm{V} 1$ lead for the suggest a right free wall of left side pathway.

Characterization of delta wave polarity in at least $2 / 3$ inferior lead (DII, DIII, AVF) with right anterolateral or right posterolateral: On the electrical side, the anterior pathway is the front will induce a depolarization of the part of the frontal muscle and then the pulse gradually spreads to the rear, towards the inferio zone causing the positive delta wave and vice versa. The posterior pathway will previous depolarization of the part of the posterior and lower muscle have impulses from the rear and right down to acrross the kent bridge and then the pulse towards as well as spread gradually to the left and front zone, creating negative delta wave at the previous QRS complex in inferior lead.

The results showed that build to a group of "right anterolateral pathways" had positive delta wave was most common at least $2 / 3$ inferior lead are noted (95.8\%), and group of 'includes right lateral and right posterolateral pathways" had negative delta wave was most common at least $2 / 3$ inferior lead as above with hight accuracy $(93,5 \%)$, beside results showed that very difficult 
in localizing between two position were right lateral and right posterolateral APs, can be explained by the two locations have similar in electrophysiological side.

According to the statistics as above, the right lateral and right posterolateral pathways are often found in the negative delta wave in at least $2 / 3$ inferior lead.

This suggests that only based on these parameters will predict with very high accuracy for the right anterolateral and right posterolateral pathways, but it is difficult to predicting the discrimination of the right lateral and right posterolateral, because these two regions (RL and RPL region) have the same characteristic of negative delta wave in at least $2 / 3$ inferior lead.

We performed the characteristic of QRS complex polarity at least 2/3 inferior lead in these two regions. Result showed that the right lateral position was most common with positive QRS complex at least 2/3 inferior lead (90\%); While, the right lateral was most common with negative QRS complex at least $2 / 3$ inferior lead $(95.2 \%)$. Thus, this parameter (QRS complex polarity) helped to suggesting that the right lateral or right posterolateral pathways.

On the electrical side, the RL/RPL pathways is lower anastomose on the right lower heart is due to pathways will previous depolarization of the part of the lower muscle as inferior zone causing the negative delta wave in inferior lead. The difference in value on the QRS complex in the inferior lead for the $\mathrm{RL}$ and RPL is due to RL pathways will previous depolarization of the part of the lower muscle and then the pulse propagated through the ventricular wall to the his bundle causing about face vector to make the image of $\mathrm{Q}$ wave counterfeit, so the RL pathways will be a previous negative delta waveform while the positive QRS complex. The RPL pathways is depolarization pass through the front kent bridge to the downstroke, make to a false QS image, so that the RPL region had both in negative QRS complex and negative delta wave in at least $2 / 3$ inferior lead [15].

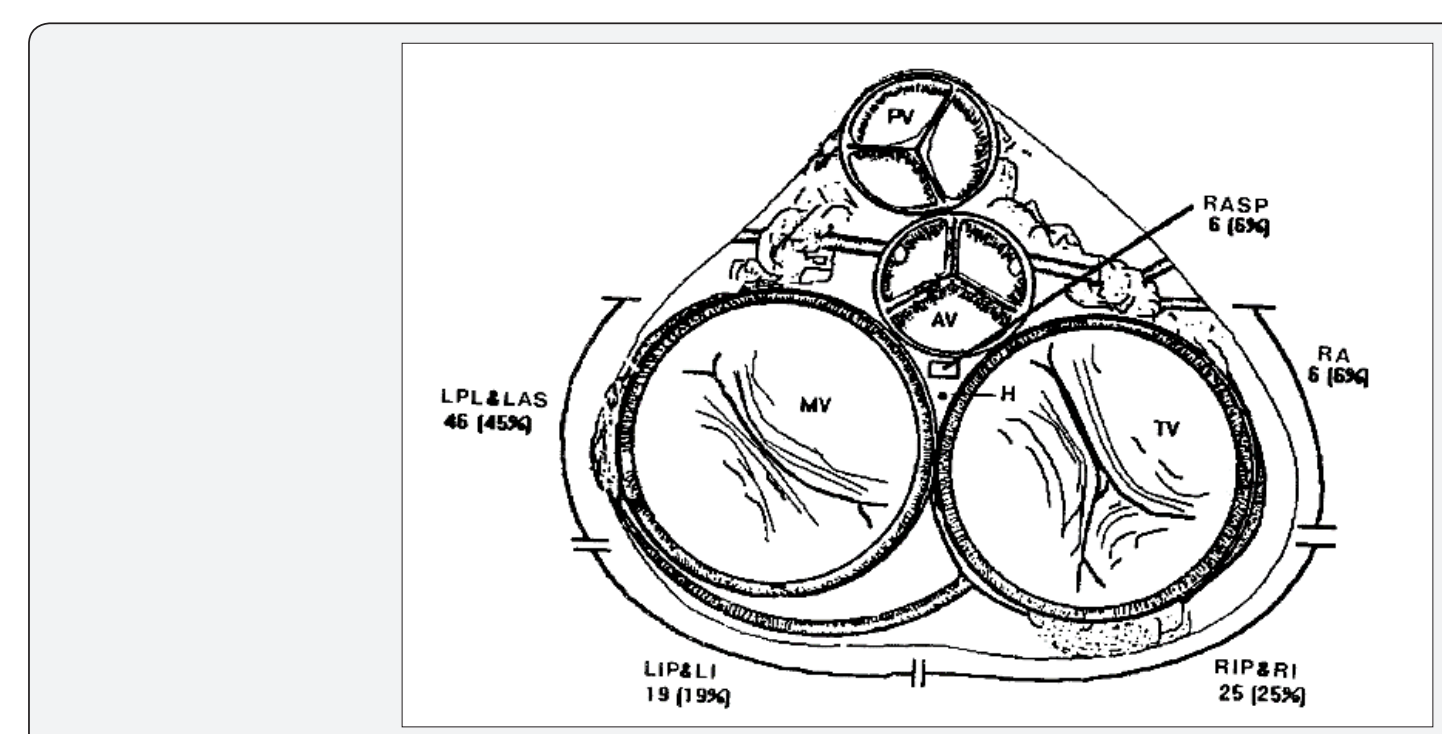

Figure 3: Cross-sectional diagram of the heart at the level of the atrioventricular ring. RA: Right anterior, RIP: Right inferior paraseptal, RI: Right inferior [12].

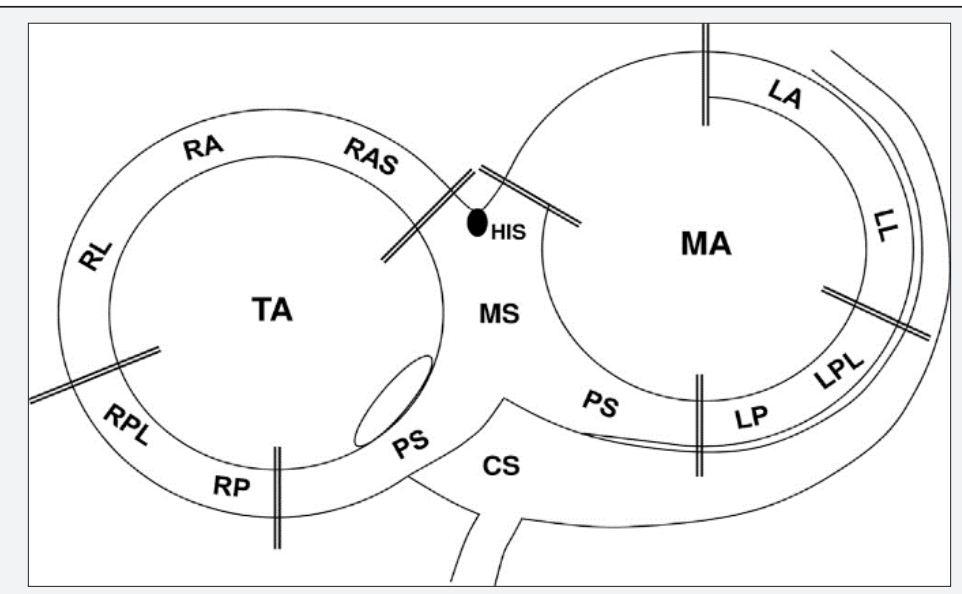

Figure 4: Anatomic definition of accessory pathway location RA: Right anterior, RL: Right lateral, RPL: Right posterolateral, RP: Right posterior [13]. 


\section{Journal of Cardiology \& Cardiovascular Therapy}

Many studies showed that difficulty in localizing between other positions of right free wall pathways. Andre D' Avila showed that right posteroseptal (RPS) had positive QRS complex in DIII lead, but not-yet localizing between two location as above [6]. Many studies not-yet localizing between other right free wall as Pedro was used to characteristic of QRS polarity in DII, V1 and V2 lead, can be add to positions (RIP, RI) by one location; Pedro Iturralde selected two locations of right free wall were right anterolateral (RA) and group of "includes RIP \& RI pathways" (Figure 3) [12]. Noriko was used to R/S in V1, V2, AVF, and inferior lead can localizing right anteroseptal-anterolateral and right lateral (RAS, RA, RL) defined by one location with characteristic were $\mathrm{R} / \mathrm{S}$ ratio $<0.5$ in $\mathrm{V} 1$ and $\mathrm{V} 2$ lead, $\mathrm{R} / \mathrm{S}$ ratio $<1$ in aVF lead; Noriko Taguchi selected two locations were "includes RA \& RL pathways" and "includes RPL \& RP pathways" (Figure 3 \& 4) [13].

Thus, We have been predicted "right anterolateral" or "includes right lateral and right posterolateral pathway" by positive/negative delta wave in at least $2 / 3$ inferior, different between right lateral and right posterolateral location by positive or negative QRS complex in at least 2/3 inferior lead; which can help the doctors to perform a rapid onset of accessory pathway location on the tricuspid valve forwards or backwards, or within 1-2 $\mathrm{cm}$ of the valve; help to facilitate mapping techniques and shorten time radiofrequency ablation $[1,2]$.

\section{Accuracy of new ECG algorithm for localizing righ free wall accessory pathways}

We were developed a new algorithm using some simple ECG parameters as right free wall belong to right side pathways by negative delta wave at V1 lead, right free wall sites accessory pathways by QRS complex transition at after V1V2 lead. "Right anterolateral" and group of "include right lateral and right posteraolateral" sites accessory pathways by positive/negative delta waves in at least $2 / 3$ inferior, but "right lateral" and "right posterolateral" by positive/negative QRS complex in at least $2 / 3$ inferior lead. Then this algorithm was tested prospectively in 23 patients were compared with the location of accessory pathway's successful ablation by RF, and Calculate for sensitivity, specificity, positive predictive value and negative predictive value of the diagnosed algorithm for accessory pathway sites were high accuracy (Table 3-4 \& 4-1).

Table 3: Characterization of delta wave polarity in at least 2/3 inferior lead (DII, DIII, aVF).

\begin{tabular}{|c|c|c|c|c|c|c|c|c|}
\hline \multirow{2}{*}{$\begin{array}{c}\text { Location } \\
(+/-) \text { Delta wave in inferior lead }\end{array}$} & \multicolumn{2}{|c|}{$\begin{array}{l}\text { Right antero } \\
\text { lateral (n) }\end{array}$} & \multicolumn{2}{|c|}{$\begin{array}{l}\text { Right lateral } \\
\text { (n) }\end{array}$} & \multicolumn{2}{|c|}{$\begin{array}{c}\text { Right postero } \\
\text { lateral (n) }\end{array}$} & \multicolumn{2}{|c|}{ Total } \\
\hline & $\mathbf{n}$ & $\%$ & $\mathbf{n}$ & $\%$ & $\mathbf{n}$ & $\%$ & $\mathbf{n}$ & $\%$ \\
\hline Positive delta wave in at least $2 / 3$ inferior & 14 & 100.0 & 1 & 7.7 & 0 & 0.0 & 10 & \\
\hline Negative delta wave in at least $2 / 3$ inferior & 0 & 0.0 & 12 & 92.3 & 23 & 100.0 & 13 & \\
\hline Total (n) & 14 & & 13 & & 23 & & 50 & \\
\hline
\end{tabular}

Table 4: Characterization of QRS complex polarity in at least 2/3 inferior lead (DII, DIII, aVF).

\begin{tabular}{|c|c|c|c|c|c|c|c|c|}
\hline \multirow{2}{*}{ Location $Q R S$ complex polarity } & \multicolumn{2}{|c|}{$\begin{array}{c}\text { Right } \\
\text { Anterolateral }\end{array}$} & \multicolumn{2}{|c|}{$\begin{array}{l}\text { Right } \\
\text { lateral }\end{array}$} & \multicolumn{2}{|c|}{ Right posterolateral } & \multicolumn{2}{|c|}{ Total } \\
\hline & $\mathbf{N}$ & $\%$ & $\mathbf{n}$ & $\%$ & $\mathbf{n}$ & $\%$ & $\mathbf{n}$ & $\%$ \\
\hline Positive QRS complex & 14 & 100.0 & 12 & 92.3 & 2 & 8.7 & 28 & 56.0 \\
\hline Negative QRS complex & 0 & 0.0 & 1 & 7.7 & 21 & 91.3 & 22 & 44.0 \\
\hline Total (n) & 14 & & 13 & & 23 & & 50 & 100.0 \\
\hline
\end{tabular}

Table 4-1: Comparision of procedural parameters in other studies about procedure time and fluoroscopy.

\begin{tabular}{|c|c|c|c|}
\hline Authors & $\begin{array}{c}\text { Accessory pathway } \\
\text { location }\end{array}$ & $\begin{array}{l}\text { Mean Procedure } \\
\text { time (minute) }\end{array}$ & $\begin{array}{l}\text { MeanFluoroscopy } \\
\text { time (minute) }\end{array}$ \\
\hline Robert Lemery [3] & WPW syndrome $(n=60)$ & $216.0 \pm 90.0$ & $66.0 \pm 33.0$ \\
\hline Tran Van Dong [5] & Typical WPW (n = 96) & $96.3 \pm 44.6$ & $23.1 \pm 13.6$ \\
\hline Tran Van Dong [5] & Right free wall lateral $(n=29)$ & $117.1 \pm 53.7$ & $31.1 \pm 16.3$ \\
\hline Our results (2016-2017) & Right free wall lateral $(n=50)$ & $50.2 \pm 11.5$ & $6.9 \pm 3.0$ \\
\hline
\end{tabular}




\section{Journal of Cardiology \& Cardiovascular Therapy}

Localization of free wall lateral locations accessory pathways group by transition characteristics of the QRS complex on 12-lead ECG: Accuracy of the algorithm for localizing
APs in right free wall location by QRS complex transition at after V1, V2 lead (V3-V6) were 22/23 (94.0\%), giving a very high sensitivity of $94.0 \%$ (Table 5 ).

Table 5: Overall, Sensitivity, Specificity, PPV and NPV Value of the Proposed Algorithm for right free wall pathway in 50 patients.

\begin{tabular}{|c|c|c|c|c|c|c|}
\hline Right free wall Accessory Pathways $(n=50)$ & Se (\%) & Sp (\%) & PPV (\%) & NPV (\%) & $\mathbf{R}$ & $\mathbf{P}$ \\
\hline The free wall lateral accessory pathways & $94.0 \%$ & & & & & \\
\hline $\begin{array}{l}\text { Right side APs (right free lateral APs) by } \\
\qquad(+) /(-) \text { delta wave in lead V1 }\end{array}$ & $98.0 \%$ & & & & & \\
\hline $\begin{array}{l}\text { Right side APs (right free lateral APs) by } \\
\qquad(+) /(-) \text { QRS in lead V1 }\end{array}$ & $100 \%$ & & & & & \\
\hline $\begin{array}{l}\text { RAL pathways with RPL region by }(+) /(-) \text { delta wave in at least } 2 / 3 \text { inferior } \\
\text { lead }\end{array}$ & $100 \%$ & $100 \%$ & $100 \%$ & $100 \%$ & 1 & 0.0001 \\
\hline RAL and RPL pathways by $(+) /(-)$ QRS in at least $2 / 3$ inferior lead & $100 \%$ & $91.3 \%$ & $100 \%$ & $91.3 \%$ & 0.894 & 0.0001 \\
\hline RAL and includes RL/RPL pathways by delta wave in at least $2 / 3$ inferior lead & $100 \%$ & $97.2 \%$ & $100 \%$ & $97.2 \%$ & 0.953 & 0.0001 \\
\hline $\begin{array}{l}\text { Includes RAL/RL and RPL pathways by QRS complex polarity in at least 2/3 } \\
\text { inferior lead }\end{array}$ & $96.3 \%$ & $91.3 \%$ & $92.9 \%$ & $95.5 \%$ & 0.880 & 0.0001 \\
\hline RL and RPL pathway by QRS complex polarity in at least $2 / 3$ inferior lead & $92.3 \%$ & $91.3 \%$ & $85.7 \%$ & $95.5 \%$ & 0.824 & 0.0001 \\
\hline
\end{tabular}

Muhammad [9] showed that septal or lateral accessory pathways by QRS complex transition at V1V2 or after V1V2 lead with Se of $97 \%$ and Sp of $95 \%$. Years ago, Giorgi studies on 41 patients, add to right anteroseptal and right anterolateral by a location were call that ARV (Anterior right Ventricle) and explained by those accessory pathways had small QRS complex; the accuracy of ARV location with Se of $96.5 \%$, Sp of $90.7 \%$, PNP of $80 \%$ [11]; the results were not-yet characteristic defined for between anteroseptal and right anterolateral pathways. D' Avila was used to characteristic of QRS complex polarity in DIII lead, the results showed that value of predicting for the right free wall APs with Se of $100 \%$, Sp of $98 \%$ and PNV of $70 \%$ [6].

Localization of left accessory pathway pathways by delta wave polarity in V1 lead: Accuracy of the algorithm for localizing APs in right free wall pathways belong to right location by negative delta wave most common at V1 lead were $22 / 23$ patients (98.0\%), giving a high sensitivity of $98.0 \%$.

Chern-En Chang [7] showed that the Left side or right-side pathways by positive/negative delta wave at V1 lead with Se of
94.4\% and Sp of $87.5 \%$. Years ago, Milstein (n=141) used to some parameters as the characteristic of $\mathrm{Q}$ wave or isoelectric QRS in DI, AVL, V1, inferior lead, Rs or RS in V1, V2, or V3 lead, and QRS axis, can be predicting for the right free wall with Se of 75\%, Sp of $98.5 \%$, PNV of $50 \%[10]$.

\section{Localization of other location of right free wall pathways}

a) Localization of other position of right free wall pathways by positive delta wave or negative delta wave in at least $2 / 3$ inferior lead

Accuracy of the algorithm for localizing APs in group of "right anterolatetal pathways" with group of "includes right lateral and right posterolateral pathways" by positive/negative delta wave in at least $2 / 3$ inferior lead was very significantly higher, giving a sensitivity of $100 \%$, specificity of $97.2 \%$, PPV of $100 \%$ and NPV of $97.2 \%$, with $\mathrm{R}=0.953, \mathrm{P}<0.0001$. Muhammad showed that the Antero or postero accessory pathways by positive/negative delta waves in common at inferior lead had Se and Sp from 85-100\% [9] (Figure 4.1-4.3).

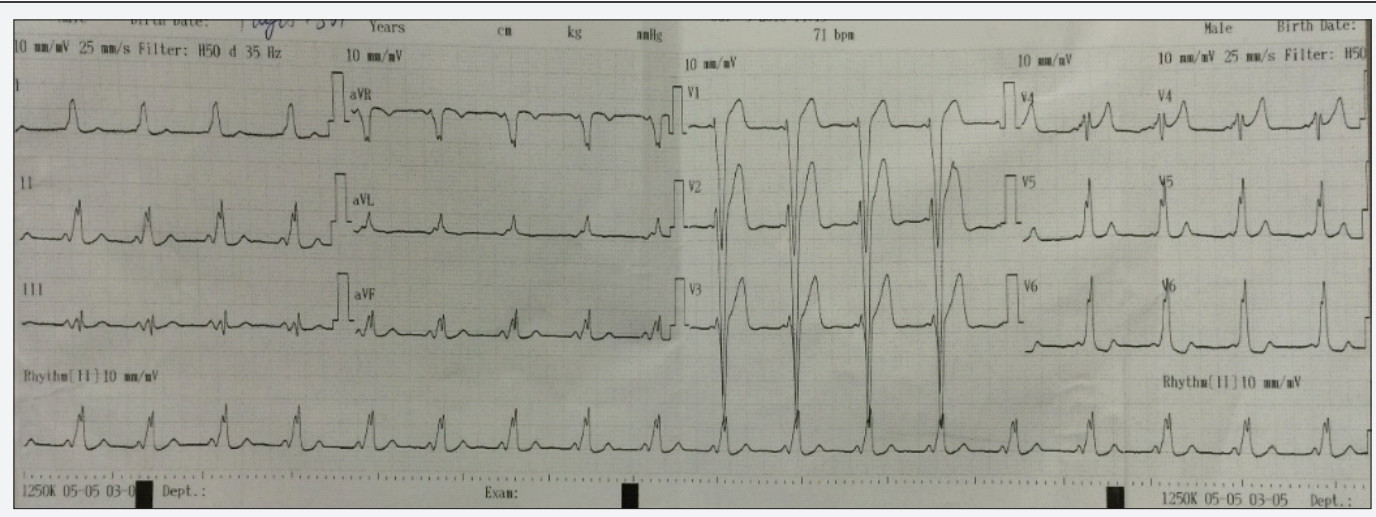

Figure 4.1: Right anterolateral (RAL). 


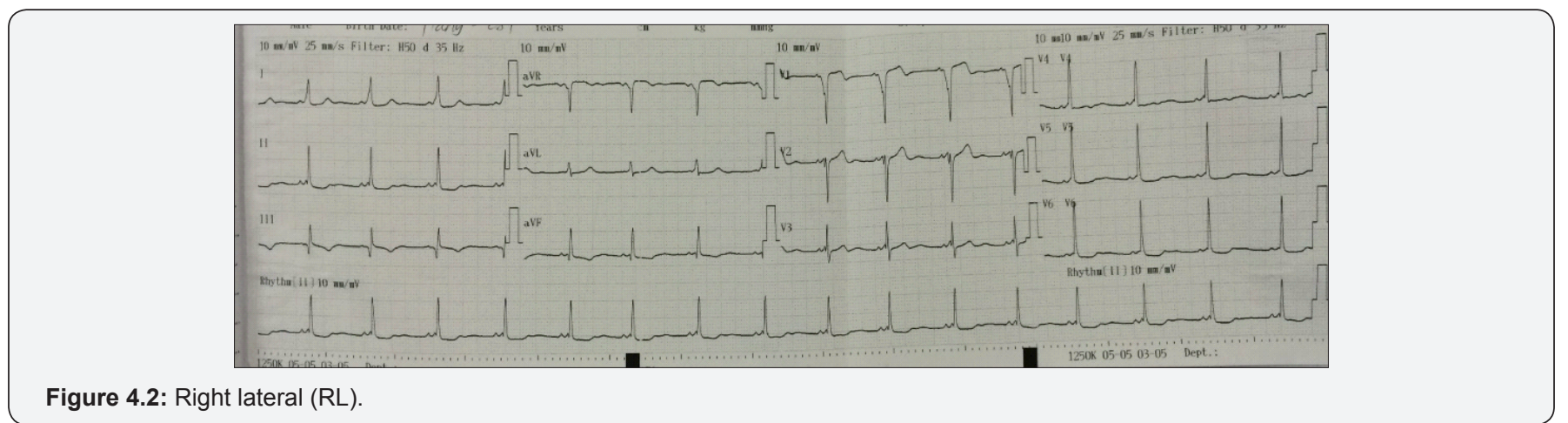

Figure 4.2: Right lateral (RL).

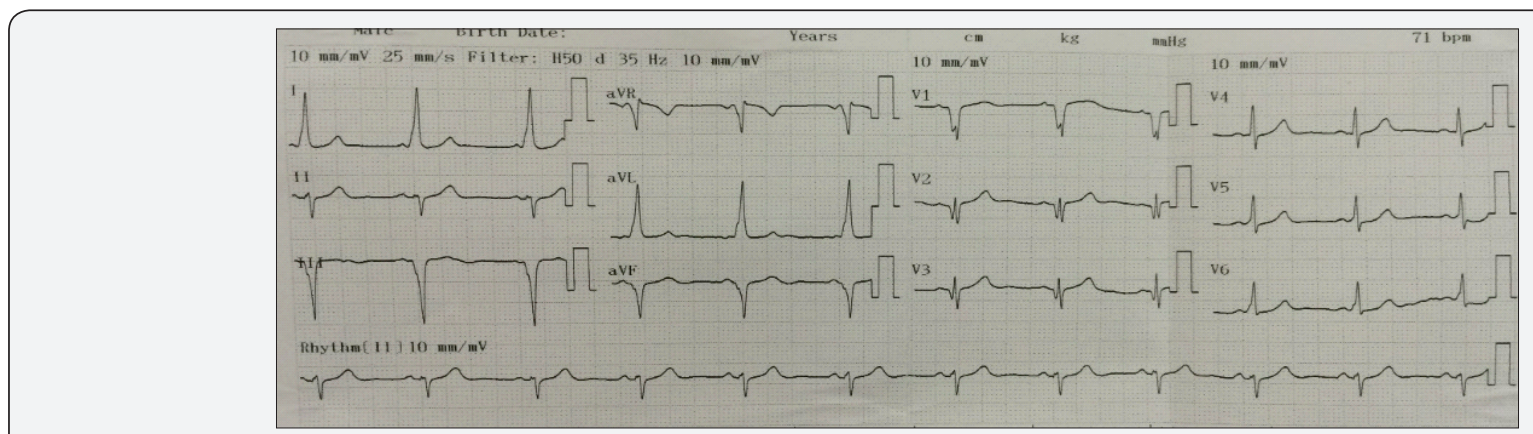

Figure 4.3: Right posterolateral (RPL).

\section{b) Localization of right lateral or right posterolateral pathways by positive/negative QRS complex in at least $2 / 3$ inferior lead}

Accuracy of the algorithm for localizing APs in right lateral or right posterolateral position by positive or negative QRS complex was very significantly higher, giving a sensitivity of $92.3 \%$, specificity of $91.3 \%$, PPV of $85.7 \%$ and NPV of $95.5 \%$ (R= 0.824 ; $\mathrm{P}<0.0001)$; However, the predictive value was not high $(66.7 \%)$; Therefore, the doctors must be attention to consideration for these cases in the during procedure of the mapping and radiofrequency ablation. Furthermore, Accuracy of the algorithm for different between the goup of "includes right anterolateral and right lateral" or "right posterolateral" position by positive or negatie QRS complex was very significantly higher, giving a sensitivity of $96.3 \%$, specificity of $91.3 \%$, PPV of $92.9 \%$ and NPV of $95.5 \%$ $(\mathrm{R}=0.880 ; \mathrm{P}<0.0001)$, giving the sensitivity very high $(96.3 \%)$; Therefore, the doctors must be consideration for two method in predicting localizations before the mapping and radiofrequency ablation.

D' Avila showed that only predicting the right free wall APs, but not localizing for the between other location (right anterolateral, right lateral, right posterolater pathways) of right free wall APs [6]. Muhammad [9] studies used to many parameters such as positive/negative delta wave in V1, DI, DII, DIII lead, and inferior leads (DII, DIII, aVF), R wave in DI, DII, DIII and V1 lead; R/S in D1, aVL and V1 lead; S wave in V1 lead and QRS axis, the studies was showed that the value of localizing in right side with sensitivity of $92 \%$ and specificity of $100 \%$; but right free wall pathways were only two locations (right antero and right posterolateral pathways) because the results showed that negative delta wave in inferior lead for the right lateral and right posterolateral pathways, therefore Muhammad was add to these positions by one location and call that righ posterolateral pathways, can be explained by the studies not-yet used to parameters as positive/negative QRS complex in inferior lead in localizing between right lateral and right posterolateral pathways [9]. We were used to the parameter (QRS complex polarity) in at least 2/3 inferior to helped accuracy for localizing Aps between two positions.

The role of the potential to predict a successful ablation site can help the fluoroscopy time and procedure time were significantly shorten, it's fluoroscopy safety because according to Singger Igor studied to mean fluoroscopy time for per case had over 48 minute and over 4 case for per weeks was cause on chromosomal aberration $[3,4]$.

\section{Conclusion}

We studied 40 patients, we have developed a new algorithm in localizing accessory pathway for the right free wall by 40 patients with typitcal WPW syndrome and validated it. We found that the right free wall had negative delta wave was most common at V1 lead (80\%) and QRS complex transition was most common at after V1V2 lead lead (90\%). Anterolateral pathways had positive delta wave was most common at least $2 / 3$ inferior lead (100\%) and right lateral as well as posterolateral pathways had negative delta wave was most common at least 2/3 inferior lead (93.5\%). Different between right lateral and right posterolateral by positive or negative QRS complex in at least 2/3 inferior lead.

Then this algorithm was tested prospectively in 50 patients were compared with the location of AP's successful ablation by RCFA. The new algorithm was proved to be high accuracy as 
sensitivity and specificity (from $91.3 \%$ to $100 \%$ ). The role of the predict AP location very important in effect of significantly shorten on the fluoroscopy time, procedure time and fluoroscopy safety when using the new algorithm with simple parameters as above for the right free wall location.

\section{References}

1. Scheinman MM (2012) The History of the Wolff-Parkinson-White Syndrome. Rambam Maimonides Med J 3(3): e0019.

2. Basiouny T (2012) Prospective Validation of a Sezer ECG Algorithm For Localization of Accrssory Pathways in Patients With Wolff-ParkinsonWhite Syndrome. AAMJ 10(3): Suppl 2.

3. Lemery R, Talajic M, Roy D, Coutu B, Lavoie L, et al. (1992) Success, safety, and late electrophysiological outcome of low-energy directcurrent ablation in patients with the Wolff - Parkinson - White syndrome. Circulation 85(3): 957-962.

4. Igor S (1993) Clinical manual of electrophysiology. Williams \& Wilkins, Baltimore, USA, pp. 52-68.

5. Dong VT (2006) Doctor of Philosophy Thesis in medicine: Research in Electrophysiology and treatment of Wolff-Parkinson-White Syndrome by Radiofrequency Catheter Ablation. Vietnam Military Medical University, Vietnam.

6. d'Avila A, Brugada J, Skeberis V, Andries E, Sosa E, et al. (1995) A Fast and Reliable Algorithm to Localize Accessory Pathways Based on the Polarity of the QRS Complex on the Surface ECG During Sinus Rhythm. Pacing Clin Electrophysiol 18(9 Pt 1): 1615-1627.

7. Chiang CE, Chen SA, Teo WS, Tsai DS, Wu TJ, et al. (1995) An Accurate Stepwise Electrocardiographic Algorithm for Localization of Accessory Pathways in Patients with Wolff-Parkinson-White Syndrome from a Comprehensive Analysis of Delta Waves and R/S Ratio During Sinus Rhythm. Am J Coll Cardiol 76(1): 40-46.
8. Arruda MS, McClelland JH, Wang X, Beckman KJ, Widman LE, et al. (1998) Development and Validation of an ECG Algorithm for Identifying Accessory Pathway Ablation Site in Wolff-Parkinson-White Syndrom. J Cardiovasc Electrophysiol 9(1): 2-12.

9. Dar MA, Shabbir HS, Abdul RA, Nadeem HM (2008) Localization of accessory pathways according to AP Fitzpatrick ECG criteria in patients with Wolff-Parkinson-White syndrome in our population. Pakistan Heart Journal 41(3-4): 21-27.

10. Milstein S, Sharma D, Guiraudeon GM, Klein GJ (1987) An Algorithm for the electrocardiographic localization of accessory pathways in the Wolff-Parkinson-White syndrome. Pacing Clin Electrophysiol 10(3 Pt 1): $555-563$

11. Giorgi C, Nadeau R, Primeau R, Campa MA, Cardinal R, et al. (1990) Comparative accuracy of the vectorcardiogram and electrocardiogram in the localization of the accessory pathway in patients with WolffParkinson-White syndrome: Validation of a new vector cardiographic algorithm by intraoperative epicardial mapping and electrophysiologic studies. Am Heart J 119(3Pt 1): 592-598.

12. Iturralde P, Araya-Gomez V, Colin L, Kershenovich S, de Micheli A, et al (1996) A New ECG Algorithm for the Localization of Accessory Pathways Using Only the Polarity of the QRS Complex. J Electrocardiology 29(4): 289-299.

13. Noriko T, Yoshida N, Yasuya I, Toshihiko Y, Shinjiro M, et al. (2013) A simple algorithm for localizing accessory pathways in patients with Wolff-Parkinson-White syndrome using only the R/S ratio. Journal of Arrhythmia 30(6): 439-443.

14. Akobeng AK (2007) Understanding diagnostic tests 1: Sensitivity, specificity and predictive values. Acta Paediatr 96(3): 338-341.

15. Surawicz B, Knilans TK (2008) Chou's Electrocardiography in clinical practice: Adult and Pediatric ( $6^{\text {th }}$ Ed). Elservier Saunders, pp: 481-508.

\begin{tabular}{l} 
Your next submission with Juniper Publishers \\
will reach you the below assets \\
- Quality Editorial service \\
- Swift Peer Review \\
- Reprints availability \\
- E-prints Service \\
- Manuscript Podcast for convenient understanding \\
- Global attainment for your research \\
- Manuscript accessibility in different formats \\
( Pdf, E-pub, Full Text, Audio) \\
- Unceasing customer service \\
Track the below URL for one-step submission \\
https://juniperpublishers.com/online-submission.php \\
\hline
\end{tabular}

